\title{
Application of machine learning methodology to assess the performance of DIABETIMSS program for patients with type 2 diabetes in family medicine clinics in Mexico
}

Yue You', Svetlana V. Doubova ${ }^{2 *}$ (D) Diana Pinto-Masis ${ }^{3}$, Ricardo Pérez-Cuevas ${ }^{4}$, Víctor Hugo Borja-Aburto ${ }^{5}$ and Alan Hubbard ${ }^{6}$

\begin{abstract}
Background: The study aimed to assess the performance of a multidisciplinary-team diabetes care program called DIABETIMSS on glycemic control of type 2 diabetes (T2D) patients, by using available observational patient data and machine-learning-based targeted learning methods.

Methods: We analyzed electronic health records and laboratory databases from the year 2012 to 2016 of T2D patients from six family medicine clinics (FMCS) delivering the DIABETIMSS program, and five FMCs providing routine care. All FMCs belong to the Mexican Institute of Social Security and are in Mexico City and the State of Mexico. The primary outcome was glycemic control. The study covariates included: patient sex, age, anthropometric data, history of glycemic control, diabetic complications and comorbidity. We measured the effects of DIABETIMSS program through 1) simple unadjusted mean differences; 2) adjusted via standard logistic regression and 3) adjusted via targeted machine learning. We treated the data as a serial cross-sectional study, conducted a standard principal components analysis to explore the distribution of covariates among clinics, and performed regression tree on data transformed to use the prediction model to identify patient sub-groups in whom the program was most successful. To explore the robustness of the machine learning approaches, we conducted a set of simulations and the sensitivity analysis with process-of-care indicators as possible confounders.

Results: The study included 78,894 T2D patients, from which 37,767patients received care through DIABETIMSS. The impact of DIABETIMSS ranged, among clinics, from 2 to $8 \%$ improvement in glycemic control, with an overall (pooled) estimate of 5\% improvement. T2D patients with fewer complications have more significant benefit from DIABETIMSS than those with more complications. At the FMC's delivering the conventional model the predicted impacts were like what was observed empirically in the DIABETIMSS clinics. The sensitivity analysis did not change the overall estimate average across clinics.

\footnotetext{
* Correspondence: svetlana.doubova@gmail.com

2Epidemiology and Health Services Research Unit, CMN Siglo XXI, Mexican Institute of Social Security, Av. Cuauhtemoc 330, Col. Doctores, Mexico City, Mexico

Full list of author information is available at the end of the article
}

(c) The Author(s). 2019 Open Access This article is distributed under the terms of the Creative Commons Attribution 4.0 International License (http://creativecommons.org/licenses/by/4.0/), which permits unrestricted use, distribution, and reproduction in any medium, provided you give appropriate credit to the original author(s) and the source, provide a link to the Creative Commons license, and indicate if changes were made. The Creative Commons Public Domain Dedication waiver (http://creativecommons.org/publicdomain/zero/1.0/) applies to the data made available in this article, unless otherwise stated. 
(Continued from previous page)

Conclusions: DIABETIMSS program had a small, but significant increase in glycemic control. The use of machine learning methods yields both population-level effects and pinpoints the sub-groups of patients the program benefits the most. These methods exploit the potential of routine observational patient data within complex healthcare systems to inform decision-makers.

Keywords: Machine learning methodology, Diabetes program, Family medicine clinics, Mexico

\section{Background}

In Mexico, type 2 diabetes (T2D) is a major public health concern. The prevalence of this condition is above $9.4 \%$ in the adult population and increasing [1]. T2D is a chronic disease characterized by a progressive loss of $\beta$-cell insulin secretion and frequent insulin resistance [2]. In poorly controlled patients, the chronic hyperglycemia causes damage of multiple organ systems and development of micro- and macrovascular complications. The manifestations of microvascular complications are nephropathy, retinopathy and neuropathy. Macrovascular complications are coronary artery disease, peripheral arterial disease, and stroke. These complications are accountable for most of the morbidity, hospitalizations, and deaths that occur in patients with diabetes mellitus [3, 4]. A recent meta-analysis of 28 randomized trials that included 34,912 T2D patients found that targeting intensive glycemic control (HbA1C $<7 \%$ ) reduces the risk of microvascular complications, compared with conventional glycemic control; yet, it also increases the risk of hypoglycemia and did not show significant differences for all-cause and cardiovascular mortality [5].

The Mexican Institute of Social Security (Spanish acronym IMSS), is the most extensive health system in Mexico with nearly 65 million affiliates provides care to approximately 3.8 million T2D adult patients. The growing demand and healthcare requirements of $\mathrm{T} 2 \mathrm{D}$ pose a heavy burden for family medicine clinics (FMCs), the frontline of IMSS healthcare. T2D patients are the second cause of consultation at FMCs, and those with acute and chronic complications, including comorbidities (i.e., hypertension) are among the top ambulatory and emergency consultations and hospital admissions [6]. Furthermore, T2D has substantial economic consequences, since in 2016, diabetes expenditures alone accounted for US\$2.5 billion [7].

T2D is a complex chronic condition that requires multidisciplinary healthcare and strict patient's adherence to reduce the risk of acute and chronic complications. The primary goal of T2D treatment is to reach glucose control (glycated hemoglobin -HbA1C- below 7\%). Conventionally, IMSS FMC consultations and follow-ups for T2D have been provided by a family doctor including physical examination, laboratory tests (i.e., blood glucose) prescription of treatment and self-care counseling. The family doctor refers patients to the dietitian, social worker, ophthalmologist or other specialists for a consultation, but the frequency of referrals and waiting time to receive multidisciplinary care might last several weeks or months due to the limited supply of these specialists and the increasing demand of patients with T2D. An analysis of the electronic health records of $25,130 \mathrm{~T} 2 \mathrm{D}$ patients found that only $13 \%$ were referred to an ophthalmologist, $3.9 \%$ received nutritional counseling, and $23 \%$ had HbA1c $<7 \%$ (or plasma glucose $\leq 130$ $\mathrm{mg} / \mathrm{dl}$ ) [8]. Though there are specific clinical guidelines for T2D treatment, care is irregular and uncoordinated [9]. Evaluations of patient outcomes of FMCs at IMSS revealed less than $30 \%$ of T2D patients achieved HbA1c below 7\% [10-12].

The need to improve health outcomes of T2D patients prompted IMSS to design and launch the DIABETIMSS program in 2008. DIABETIMSS is a comprehensive model of care that fulfills the Chronic Care Model attributes $[13,14]$. The building block of DIABETIMSS is a multidisciplinary team (medical doctor, nurse, psychologist, dietitian, dentist, and social worker) that delivers coordinated and comprehensive healthcare. In addition to regular consultations with the team, T2D patients receive individual, family and group education on self-care and prevention of complications. Only T2D patients with less than 10 years after diagnosis and without severe chronic complications are eligible to enter DIABETIMSS. The primary goal of DIABETIMSS focuses on improving patient's self-care and achieving glycemic and metabolic control (reducing high blood pressure, cholesterol levels, and excess body fat, among others). Ultimately, DIABETIMSS care is expected to avert acute complications, reduce demand for emergency services and hospitalizations and delay the progression of organ damage.

The program has expanded gradually. Currently, 91, 000 patients attend 136 DIABETIMSS program modules distributed throughout the country. DIABETIMSS introduced healthcare delivery changes for which an effectiveness evaluation is worthwhile. Previous evaluations of DIABETIMSS reported improvements in patient selfcare and reductions in blood glucose levels. However, small samples and lack of a control group limit drawing 
robust conclusions [15-17].. In fact, in complex health systems, such as IMSS, it might not be possible to evaluate a new program by design, as it can be impractical to randomize the initiation of the program across different clinics for logistic and organizational reasons; therefore, to evaluate the impact of a program one often must rely on observational data.

A new trend of statistical approaches such as machine learning methods (e.g., the approaches used herein: Targeted Learning [18, 19] and Super Learning [20]) have been developed to use routine health data (e.g., electronic health records) to adjust for confounding and produce robust results that estimate parameters, such as the average treatment effect (ATE). The use of machine learning to estimate the data-generating distribution avoids assumptions implicit in standard parametric methods, mainly when there are many factors that can influence the outcome of interest. The ensemble learning method used in this paper is Super Learning [20], which builds an ensemble learner by choosing a weighted combination of algorithms (candidate learners) to optimize the predictive performance using (V-fold) multiple cross-validations. Some of these algorithms could be parametric models, while others could be machine learning algorithms. This ensemble learner is proved to achieve oracle inequality, which means that it is optimal in most typical situations where theory does not guide on which algorithm will be most successful for a given problem. This method allows straightforward generalizations that can accommodate complex data structures, including missing and censored data. If the relevant variables have been measured (such as all confounders of the intervention), this method allows for meaningful use of the routine observational big data to obtain results with a reduced statistical bias on the health programs effects useful for decision-makers, particularly in resource-limited settings where large scale trials are not possible.

The availability of the new statistical techniques provides a unique opportunity to ascertain how the combination of routine clinical data and statistical algorithms serve to evaluate the performance of the program. Therefore, the objective of the study was to assess the performance of DIABETIMSS on glycemic control of T2D patients, using available observational patient data and machine-learning-based Targeted Learning (TMLE) methods.

\section{Methods}

We performed secondary data analysis of the electronic health record and laboratory databases from eleven IMSS' FMCs located in Mexico City and the State of Mexico, for the period 2012 to 2016. The study included six clinics with DIABETIMSS program and five clinics that provided the conventional model of care (Table 1). The FMCs were selected by convenience and comprised clinics that had complete laboratory databases for the period analyzed.

\section{Study variables}

The outcome of interest was glycemic control (yes/no, based either directly on HbA1c levels $<7 \%$ or inferred from three consecutive measurements of fasting glucose $\leq 130 \mathrm{mg} / \mathrm{dl}$ levels at the end of each year). The study

Table 1 Characteristics of family medicine clinics and number of diabetic patients included in the analysis

\begin{tabular}{|c|c|c|c|c|c|c|c|c|c|c|c|c|c|}
\hline \multirow{3}{*}{$\begin{array}{l}\text { Clinic } \\
\text { Mask } \\
N= \\
11\end{array}$} & \multirow[t]{3}{*}{ Group } & \multirow[t]{3}{*}{$\begin{array}{l}\text { Consulting } \\
\text { Rooms }^{a}(n)\end{array}$} & \multirow{3}{*}{$\begin{array}{l}\text { People } \\
\text { affiliated } \\
\text { (n) }\end{array}$} & \multicolumn{5}{|c|}{$\begin{array}{l}\text { People with type } 2 \text { diabetes with at least one medical } \\
\text { consultation during the analyzed year }\end{array}$} & \multicolumn{5}{|c|}{$\begin{array}{l}\text { People referred and attend to DIABETIMSS } \\
\text { program at least once }\end{array}$} \\
\hline & & & & 2012 & 2013 & 2014 & 2015 & 2016 & 2012 & 2013 & 2014 & 2015 & 2016 \\
\hline & & & & (n) & (n) & $(n)$ & (n) & (n) & (n) & (n) & (n) & (n) & (n) \\
\hline$A$ & Diabetimss & 16 & 76800 & 3602 & 3476 & 3636 & 4333 & 4315 & 290 & 249 & 198 & 344 & 529 \\
\hline B & Diabetimss & 21 & 100800 & 6098 & 6237 & 6372 & 6603 & 6785 & 613 & 1755 & 2223 & 1916 & 1510 \\
\hline C & Diabetimss & 25 & 120000 & 8960 & 9366 & 9749 & 10183 & 10436 & 2119 & 1818 & 1566 & 2000 & 1918 \\
\hline D & Diabetimss & 12 & 57600 & 4009 & 4125 & 4194 & 4334 & 4480 & 534 & 1274 & 1752 & 1777 & 1588 \\
\hline$E$ & Diabetimss & 10 & 48000 & 2217 & 2443 & 2560 & 2684 & 2846 & 512 & 531 & 496 & 423 & 407 \\
\hline$F$ & Diabetimss & 10 & 48000 & 2440 & 2691 & 2964 & 3049 & 3238 & 334 & 390 & 418 & 363 & 144 \\
\hline G & Conventional & 29 & 139200 & 7664 & 7862 & 8068 & 8246 & 8579 & 0 & 0 & 0 & 0 & 0 \\
\hline $\mathrm{H}$ & Conventional & 30 & 144000 & 8169 & 8324 & 8338 & 9081 & 9333 & 0 & 0 & 0 & 0 & 0 \\
\hline I & Conventional & 12 & 57600 & 3005 & 3349 & 3441 & 3611 & 3950 & 0 & 0 & 0 & 0 & 0 \\
\hline$J$ & Conventional & 10 & 48000 & 2867 & 2988 & 3040 & 3260 & 3247 & 0 & 0 & 0 & 0 & 0 \\
\hline K & Conventional & 10 & 48000 & 2475 & 2537 & 2599 & 2738 & 3031 & 0 & 0 & 0 & 0 & 0 \\
\hline Total & & 185 & 888000 & 51506 & 53398 & 54961 & 58122 & 60240 & 4402 & 6017 & 6653 & 6823 & 6,096 \\
\hline
\end{tabular}

${ }^{a}$ Each consulting room works two shifts and provides healthcare to approximately 4800 affiliates 
Table 2 Distribution of glycemic control indicator among predictors, pooled over years and clinics

\begin{tabular}{|c|c|c|c|c|}
\hline Variables & $\mathrm{HbA} 1 \mathrm{c}>=7 \%$ & $\mathrm{HbA} 1 \mathrm{c}<7 \%$ & Missing & $\begin{array}{l}\text { Adjusted } \\
p \text {-value }\end{array}$ \\
\hline Referred to DIABETIMSS, n (prop.) & & & & $<0.001$ \\
\hline No & $63284(0.50)$ & $31225(0.24)$ & $33258(0.26)$ & \\
\hline Yes & $16254(0.54)$ & $8940(0.30)$ & $4797(0.16)$ & \\
\hline Missing & $65391(0.21)$ & $23556(0.08)$ & $224410(0.72)$ & \\
\hline Previous glycemic control, n (prop.) & & & & $<0.001$ \\
\hline No & $69031(0.60)$ & $15161(0.13)$ & $30918(0.27)$ & \\
\hline Yes & $12707(0.26)$ & $19724(0.41)$ & $15628(0.33)$ & \\
\hline Missing & $63191(0.21)$ & $28836(0.09)$ & $215919(0.70)$ & \\
\hline Age, n (prop.) & & & & $<0.001$ \\
\hline$[0,53)$ & $39172(0.55)$ & $12795(0.18)$ & $19186(0.27)$ & \\
\hline$[53,62)$ & $37784(0.53)$ & $14612(0.21)$ & $18642(0.26)$ & \\
\hline$[62,71)$ & $38587(0.53)$ & $18023(0.25)$ & $16378(0.22)$ & \\
\hline$[71,116]$ & $29386(0.47)$ & $18291(0.29)$ & $15395(0.24)$ & \\
\hline Missing & $0(0.00)$ & $0(0.00)$ & $192864(1.00)$ & \\
\hline $\begin{array}{l}\text { Nutrition status at the beginning of the } \\
\text { year, } n \text { (prop.) }\end{array}$ & & & & 0.646 \\
\hline Underweight & $462(0.44)$ & $190(0.18)$ & $409(0.39)$ & \\
\hline Normal weight & $24399(0.51)$ & $10454(0.22)$ & $13326(0.28)$ & \\
\hline Overweight & $59249(0.52)$ & $25584(0.23)$ & $28164(0.25)$ & \\
\hline Obesity & $60609(0.53)$ & $27360(0.24)$ & $27228(0.24)$ & \\
\hline Missing & $210(0.00)$ & $133(0.00)$ & $193338(1.00)$ & \\
\hline Sex, n (prop.) & & & & 0.004 \\
\hline Female & $86565(0.52)$ & $38609(0.23)$ & $40071(0.24)$ & \\
\hline Male & $58364(0.52)$ & $25112(0.22)$ & $29530(0.26)$ & \\
\hline Missing & $0(0.00)$ & $0(0.00)$ & $192864(1.00)$ & \\
\hline $\begin{array}{l}\text { BMI at the beginning of the year }\left(\mathrm{kg} / \mathrm{m}^{2}\right) \text {, } \\
\mathrm{n} \text { (prop.) }\end{array}$ & & & & 0.901 \\
\hline$[11.2,26.0)$ & $36448(0.51)$ & $15636(0.22)$ & $19581(0.27)$ & \\
\hline$[26.0,28.9)$ & $36040(0.53)$ & $15495(0.23)$ & $16969(0.25)$ & \\
\hline$[28.9,32.4)$ & $36242(0.53)$ & $15979(0.23)$ & $16096(0.24)$ & \\
\hline$[32.4,85.4]$ & $35989(0.52)$ & $16478(0.24)$ & $16481(0.24)$ & \\
\hline Missing & $210(0.00)$ & $133(0.00)$ & $193338(1.00)$ & \\
\hline $\begin{array}{l}\text { Height at the beginning of the year }(m) \text {, } \\
n \text { (prop.) }\end{array}$ & & & & 0.003 \\
\hline$[1.30,1.50)$ & $37877(0.54)$ & $16438(0.23)$ & $16342(0.23)$ & \\
\hline$[1.50,1.57)$ & $39267(0.53)$ & $17393(0.23)$ & $17526(0.24)$ & \\
\hline$[1.57,1.64)$ & $33231(0.52)$ & $14773(0.23)$ & $16363(0.25)$ & \\
\hline$[1.64,2.10]$ & $34344(0.50)$ & $14984(0.22)$ & $18896(0.28)$ & \\
\hline Missing & $210(0.00)$ & $133(0.00)$ & $193338(1.00)$ & \\
\hline Weight at the beginning of the year (kg), n (prop.) & & & & $<0.001$ \\
\hline$[30,63)$ & $37150(0.52)$ & $15744(0.22)$ & $18099(0.25)$ & {$[30,63)$} \\
\hline$[63,72)$ & $36771(0.52)$ & $16188(0.23)$ & $17106(0.24)$ & {$[63,72)$} \\
\hline$[72,82)$ & $35912(0.53)$ & $15694(0.23)$ & $16594(0.24)$ & {$[72,82)$} \\
\hline$[82,198]$ & $34886(0.51)$ & $15962(0.23)$ & $17328(0.25)$ & {$[82,198]$} \\
\hline Missing & $210(0.00)$ & $133(0.00)$ & $193338(1.00)$ & \\
\hline
\end{tabular}


Table 2 Distribution of glycemic control indicator among predictors, pooled over years and clinics (Continued)

\begin{tabular}{|c|c|c|c|c|}
\hline Variables & $\mathrm{HbA} 1 \mathrm{c}>=7 \%$ & $\mathrm{HbA} 1 \mathrm{c}<7 \%$ & Missing & $\begin{array}{l}\text { Adjusted } \\
p \text {-value }\end{array}$ \\
\hline Obesity, n (prop.) & & & & 0.247 \\
\hline No & $24861(0.50)$ & $10644(0.22)$ & $13735(0.28)$ & \\
\hline Yes & $119858(0.53)$ & $52944(0.23)$ & $55392(0.24)$ & \\
\hline Missing & $210(0.00)$ & $133(0.00)$ & $193338(1.00)$ & \\
\hline $\begin{array}{l}\text { Patients with Risk Factors (smoking, hypertension, } \\
\text { dyslipidemia), n (prop.) }\end{array}$ & & & & 0.022 \\
\hline No & $24358(0.50)$ & $9576(0.20)$ & $14853(0.30)$ & \\
\hline Yes & $120571(0.53)$ & $54145(0.24)$ & $54748(0.24)$ & \\
\hline Missing & $0(0.00)$ & $0(0.00)$ & $192864(1.00)$ & \\
\hline Smoking Habit, n (prop.) & & & & $<0.001$ \\
\hline No & $141903(0.52)$ & $62119(0.23)$ & $68196(0.25)$ & \\
\hline Yes & $3026(0.50)$ & $1602(0.27)$ & $1405(0.23)$ & \\
\hline Missing & $0(0.00)$ & $0(0.00)$ & $192864(1.00)$ & \\
\hline Type of insurance, $n$ (prop.) & & & & 0.027 \\
\hline Others & $74686(0.53)$ & $31175(0.22)$ & $36123(0.25)$ & \\
\hline Parents insured/Retired & $70243(0.52)$ & $32546(0.24)$ & $33478(0.25)$ & \\
\hline Missing & $0(0.00)$ & $0(0.00)$ & $192864(1.00)$ & \\
\hline Year, n (prop.) & & & & $<0.001$ \\
\hline 2012 & $28445(0.30)$ & $11297(0.12)$ & $54481(0.58)$ & \\
\hline 2013 & $27127(0.29)$ & $10916(0.12)$ & $56180(0.60)$ & \\
\hline 2014 & $29070(0.31)$ & $12264(0.13)$ & $52889(0.56)$ & \\
\hline 2015 & $30468(0.32)$ & $13582(0.14)$ & $50173(0.53)$ & \\
\hline 2016 & $29819(0.32)$ & $15662(0.17)$ & $48742(0.52)$ & \\
\hline Total number of diabetes complications, n (prop.) & & & & $<0.001$ \\
\hline 0 & $77522(0.50)$ & $36812(0.24)$ & $40760(0.26)$ & \\
\hline 1 & $45655(0.54)$ & $19015(0.22)$ & $20236(0.24)$ & \\
\hline$>1$ & $21752(0.57)$ & $7894(0.21)$ & $860522)$ & \\
\hline
\end{tabular}

The adjusted p-value is derived by tting a generalized estimating equations (GEE) with all the predictors, adjusting for patient ID. Then we did analysis of 'Wald statistic' with binomial model and logit link to obtain the $p$-value. Specifically, the $R$ function is: $t=$ geeglm (formula $=$ indic 10 curr diabetimss + edad + sexo + tipo pac + anttab + pesoini + tallaini + imclni + EdoNutriciolni + facriesg + tot enfcrondiab + SobObes + indic10 prev + year, family = binomial (link = "logit"), data = all complete, id = a l, corstr = "exchangable", std.err = "san.se" anova (t)

covariates were: patient sex, age, anthropometric data and nutritional status, history of glycemic control in the year before attending DIABETIMSS, presence, and the number of chronic diabetic complications (diabetic nephropathy, diabetic retinopathy, peripheral neuropathy and peripheral vascular disease) and other comorbidities, such as cardio-vascular diseases (Additional file 1: Table S1). We also explored the following indicators of the quality of the process of care [8]: 1. At least one measurement of HbA1c; 2. Comprehensive foot evaluation; 3. Referral to the ophthalmologist to screen for diabetic retinopathy. 4. Nutritional counseling. 5. Overweight/obese patients receiving metformin, unless contraindicated; 6. Patients with hypertension receiving inhibitors of angiotensin- converting enzyme or angiotensin-receptor blocker, unless contraindicated; 7. Patients aged $>40$ years with one or more of the following risk factors for cardiovascular diseases: smoking, hypertension, dyslipidemia, receiving 75-150 mg/day of acetylsalicylic acid unless contraindicated.

\section{Construction of the analytical database}

A structured query language was used to extract the information from the original databases and create the analytical database. The non-plausible values were predefined for the following variables: blood pressure (systolic blood pressure $<50$ or $>250 \mathrm{mmHg}$ and diastolic blood pressure $<40$ or $>200 \mathrm{mmHg})$, height $(<130$ or $>250 \mathrm{~cm})$, weight $(<30$ or $>200 \mathrm{~kg})$, HbA1c $(<3.0)$ and fasting 
plasma glucose $(<37 \mathrm{mg} / \mathrm{dl})$. The analysis excluded all non-plausible values that varied among variables from 0.5 to $1.5 \%$. SAS statistical package (V9.2) was used to construct the study variables from the extracted data.

\section{Statistical analysis}

We used relatively new machine learning-based estimators of our intervention impacts of interest (Further details of the definition of the parameters of interest, the estimators and methods for robust inference are in the Supplemental Materials file). The purpose of using such methodology was to create an estimation scheme that avoided unnecessary parametric assumptions, where model selection could be automated towards our goals of interest and would return robust statistical inference.

The data were assumed to be derived on independent individuals with repeated observations (up to 5 depending on enrollment and drop-out). For the treatment impacts, we estimated the average treatment effect (ATE) which can be thought of as a nonparametrically adjusted mean difference in patients in and out of the
DIABETIMSS program [21]. We estimated the association parameter separately by each clinic, but we averaged over the repeated years of the study. We evaluated the ATE's by using a targeted machine learning or in shorthand, Targeted Learning (TL) [18]. To use such an approach, one must estimate both an outcome prediction model and an intervention (DIABETIMSS) model. To do so in an automated and flexible manner, we used a TL approach [18] developed for the programming language $\mathrm{R}$ [22]. Internal to this algorithm are initial fits to the distribution (before a targeting step), and that was done using an ensemble machine learning approach [18, 23]. This approach avoids the pitfalls of overly reliance on a single prediction algorithm, allowing for good fits regardless of whether the true model is complex or relatively smooth and straightforward. Besides clinic-specific estimates of the impact of the program, we also created estimates pooled over the intervention clinics to derive average estimate impacts. For all our estimates, we also reported those based upon unadjusted analyses, comparing the proportion of glucose for subject observations

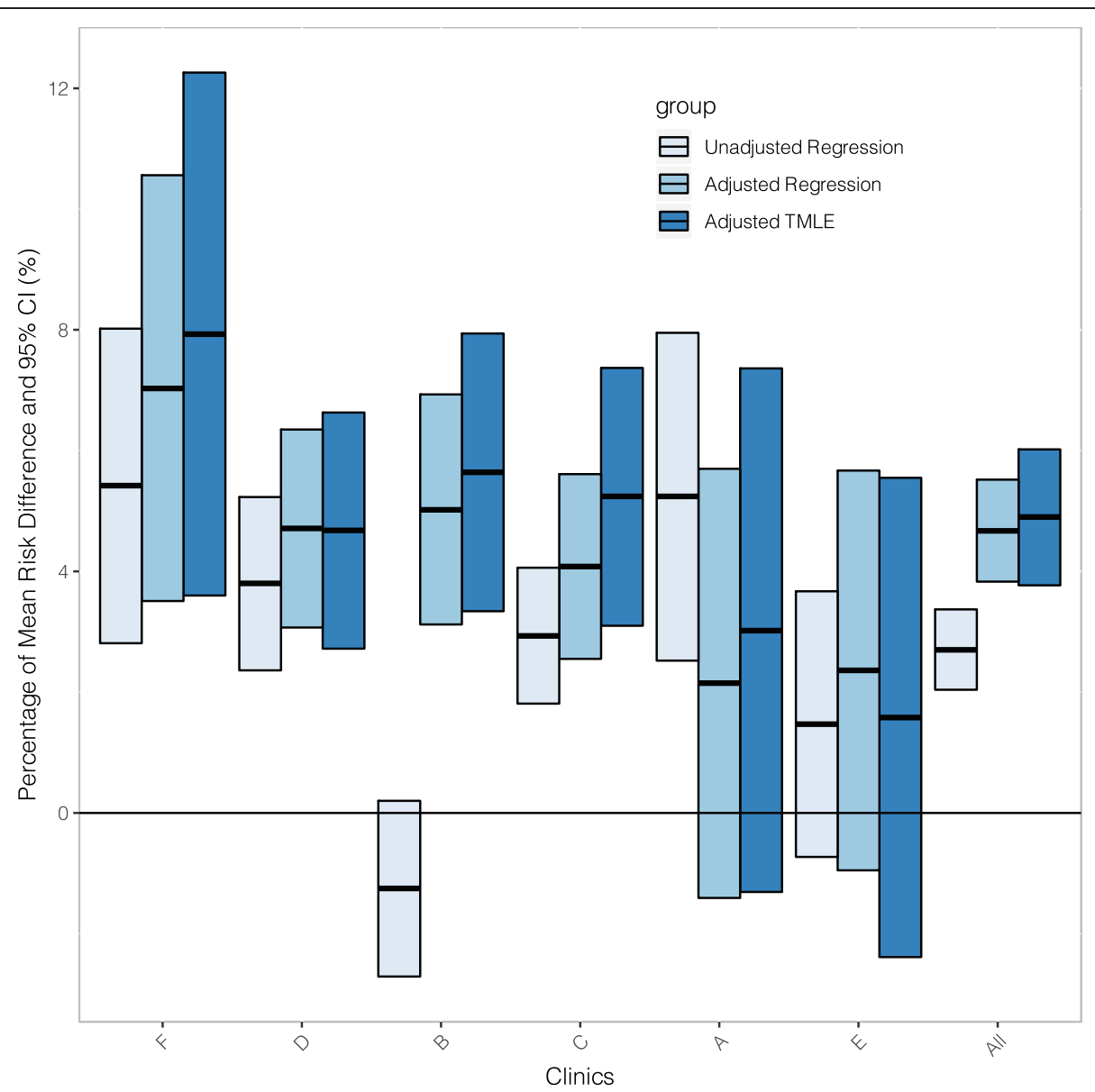

Fig. 1 Targeted Learning adjusted associations of DIABETIMSS and glucose control (estimated difference in the percentage of those with HbA1C in two groups) for all DIABETIMSS clinics and all clinics combined (the "All") 
both in and out of the program. Also, we reported estimates where we used standard multivariate logistic regression for comparison.

We only had significant missing information on the outcome (62\% of observations were missing) and performed complete case analysis assuming the data were missing at random [24, 25]. That is, we assumed there were no other (outcome) predictive covariates available to explain missingness beyond what we used in our models; this means that the conditional regression estimates assume the data are missing at random. We performed standard principal component analysis to compare the covariates for patients with and without missing outcome, and another standard principal component analysis to ensure that clinics had a similar distribution of predictor variables among their populations.

Beyond the analyses of overall intervention impacts, we also attempted to identify patient sub-groups in whom the program had the most significant intervention impacts. We did so by using the machine learning algorithms to predict treatment impact on each of the subject observations in clinics without DIABETIMSS program. Then, we used regression tree, specifically the rpart function in $\mathrm{R}$ [26] where the outcome was the estimated (predicted) treatment impact, and the covariates were covariates for which we adjusted in the primary analyses of DIABETIMSS impact on glucose control. This method of finding groups with differential treatment impacts can be considered as a tool of precision medicine, and widely used in literature $[27,28]$.

To explore the greater robustness of the TL approach relative to standard biomedical (epidemiological) regression analyses, we conducted a set of simulations, and compared the performance of the estimates and the confidence intervals of competing methods. Details of the simulations can be found in the Supplemental Materials file.

For sensitivity analysis, we adjusted for the processof-care indicators in addition to the original adjustment variables, to see if overall associations were importantly different. Thus, in addition to duplicating the analyses, we also look at the distribution of the estimated propensity score.

Table 3 Associations of DIABETIMSS program and glycemic control indicator by clinic and pooled over all clinics

\begin{tabular}{|c|c|c|c|c|c|}
\hline Clinic & DIABETIMSS & $n$ & Unadjusted logistic regression & Adjusted logistic regression & TMLE \\
\hline & & & $\mathrm{HbA} 1 \mathrm{c}<7 \%(95 \% \mathrm{Cl})$ & $\mathrm{HbA} 1 \mathrm{c}<7 \%(95 \% \mathrm{Cl})$ & $\mathrm{HbA1c}<7 \%(95 \% \mathrm{Cl})$ \\
\hline \multirow[t]{3}{*}{ A } & No & 4778 & $0.3599(0.3517,0.3680)$ & $0.3692(0.3574,0.3810)$ & $0.3694(0.3577,0.3812)$ \\
\hline & Yes & 573 & $0.4122(0.3864,0.4381)$ & $0.3907(0.3564,0.4249)$ & $0.3997(0.3665,0.4329)$ \\
\hline & $\mathrm{RD}$ & & $0.0524(0.0252,0.0795)$ & $0.0215(-0.0141,0.0570)$ & $0.0302(-0.0131,0.0736)$ \\
\hline \multirow[t]{3}{*}{ B } & No & 6335 & $0.4027(0.3950,0.4103)$ & $0.4028(0.3918,0.4138)$ & $0.4034(0.3926,0.4143)$ \\
\hline & Yes & 2324 & $0.3901(0.3777,0.4025)$ & $0.4530(0.4368,0.4693)$ & $0.4598(0.4444,0.4752)$ \\
\hline & $\mathrm{RD}$ & & $-0.0125(-0.0271,0.0020)$ & $0.0502(0.0312,0.0693)$ & $0.0564(0.0334,0.0794)$ \\
\hline \multirow[t]{3}{*}{ C } & No & 11535 & $0.3419(0.3369,0.3470)$ & $0.3285(0.3222,0.3349)$ & $0.3291(0.3228,0.3354)$ \\
\hline & Yes & 3269 & $0.3713(0.3612,0.3814)$ & $0.3694(0.3554,0.3833)$ & $0.3815(0.3673,0.3957)$ \\
\hline & $\mathrm{RD}$ & & $0.0293(0.0181,0.0406)$ & $0.0408(0.0255,0.0561)$ & $0.0524(0.0310,0.0737)$ \\
\hline \multirow[t]{3}{*}{ D } & No & 3500 & $0.3067(0.2982,0.3151)$ & $0.2911(0.2801,0.3022)$ & $0.2917(0.2809,0.3026)$ \\
\hline & Yes & 2208 & $0.3446(0.3330,0.3563)$ & $0.3382(0.3252,0.3513)$ & $0.3385(0.3257,0.3513)$ \\
\hline & $\mathrm{RD}$ & & $0.0380(0.0236,0.0523)$ & $0.0471(0.0307,0.0635)$ & $0.0468(0.0272,0.0663)$ \\
\hline \multirow[t]{3}{*}{ E } & No & 1050 & $0.1570(0.1483,0.1657)$ & $0.1624(0.1503,0.1746)$ & $0.1623(0.1501,0.1744)$ \\
\hline & Yes & 229 & $0.1717(0.1514,0.1919)$ & $0.1860(0.1551,0.2169)$ & $0.1781(0.1493,0.2069)$ \\
\hline & $\mathrm{RD}$ & & $0.0147(-0.0073,0.0367)$ & $0.0236(-0.0095,0.0567)$ & $0.0158(-0.0239,0.0555)$ \\
\hline \multirow[t]{3}{*}{$\mathrm{F}$} & No & 1160 & $0.2049(0.1944,0.2154)$ & $0.2370(0.2219,0.2520)$ & $0.2376(0.2226,0.2527)$ \\
\hline & Yes & 337 & $0.2590(0.2352,0.2828)$ & $0.3073(0.2753,0.3393)$ & $0.3169(0.2844,0.3494)$ \\
\hline & $\mathrm{RD}$ & & $0.0542(0.0281,0.0802)$ & $0.0703(0.0351,0.1056)$ & $0.0793(0.0360,0.1226)$ \\
\hline \multirow[t]{3}{*}{ All } & No & 28325 & $0.3278(0.3247,0.3309)$ & $0.3225(0.3184,0.3266)$ & $0.3227(0.3185,0.3268)$ \\
\hline & Yes & 8940 & $0.3548(0.3489,0.3608)$ & $0.3692(0.3617,0.3768)$ & $0.3716(0.3639,0.3794)$ \\
\hline & $\mathrm{RD}$ & & $0.027(0.0204,0.0337)$ & $0.0467(0.0383,0.0552)$ & $0.0490(0.0377,0.0602)$ \\
\hline
\end{tabular}

The estimates displayed in this table represent the proportion of subjects with $\mathrm{HbA1c}<7 \%$ within each group (DIABETIMSS Yes/No) as well as the difference of these proportions in the two groups. We show three estimators as discussed in text: unadjusted, adjusted within a logistic regression and finally using targeted maximum likelihood estimation (TMLE) 


\section{Results}

The study included up to 78,894 T2D patients that had at least one medical consultation at an FMC during the years analyzed (2012-2016). During this period, 37,767 patients were referred to and attended the DIABETIMSS program at least once (Table 1).

The analysis of simple unadjusted mean differences found a more significant proportion of patients who achieved glycemic control in the DAIBETIMSS program versus not (30 versus 24\%). The recent history of glycemic control was a strong predictor of current glycemic control: $61 \%$ of patients that had glycemic control during the last year had control in the next year, where only $18 \%$ of patients that had lack of control in the previous year, achieved control the following year $(p<0.01)$. There was a significant positive association of age and the glycemic control, but the missing observations drove it. No anthropometric nor nutrition-related variables were related to glycemic control. Those that had multiple risk factors had unexpectedly similar glycemic

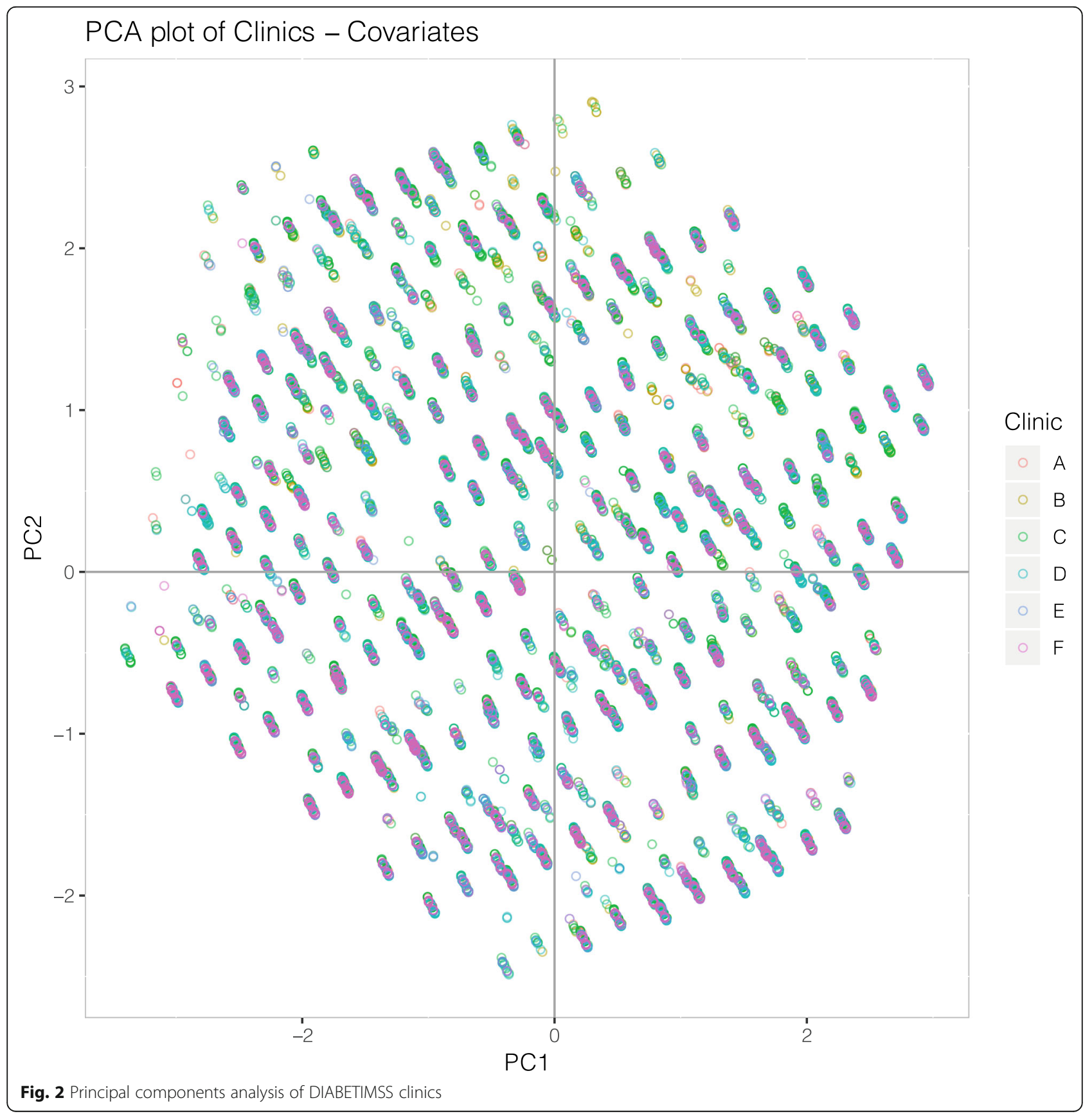


control as those with no risk factors (24\% versus $20 \%)$. There was a trend of less glycemic control among those patients with more complications related to diabetes in subjects (24\% with no complications, $21 \%$ among those with $>1$ complication) (Table 2).

The estimation of the impact of the program revealed that comparing the TMLE results across clinics and pooled ("All" clinics) results, there was a fair amount of variability in the treatment impact; ranging from 2 to $8 \%$ improvement in glycemic control, with an overall (pooled) estimate of 5\% improvement. Comparing the unadjusted to the two adjusted estimates (standard regression and machine-learning adjusted TMLE) showed strong evidence of confounding by the measured factors. For most clinics, the adjusted estimates were generally more significant than the unadjusted (Fig. 1 and Table 3).

To explore whether some clinics had very different distributions of predictors, we performed a standard principal component analysis (PCA) and colored the points on a resulting PCA plot by each clinic (Fig. 2), which shows consistent overlap among clinics. This finding suggests that there were no dramatic differences in covariate distributions among the 6 DIABETIMSS program clinics. The results of running logistic regression stratified by clinic also showed a relatively consistent associations of covariates across clinics (Additional file 1: Figure S3).

The distribution of estimated individual treatment effect (Additional file 1: Figure S4) showed a relatively notable extent of heterogeneity. To explain this heterogeneity, we performed regression tree on the blipfunction transformed data $\left(Y^{*}\right)$ to explore the factors most responsible for differences in the treatment impact. Regression tree is a simple form of histogram regression based on binary splits on covariates. It results in distinct nodes (representing sub-populations) that "best" characterize the variability seen in the outcome (in our case, the blip function). We found that the terminal nodes (the smallest subgroups) vary in their treatment impact from relatively low (2.6\% in the leftmost node) to modestly larger than the average treatment effect $(6.4 \%)$. If we examine the variables that define these splits, if there is a general message, it is that those with fewer existing complications of diabetes appear to have a more significant benefit from the program than those with more

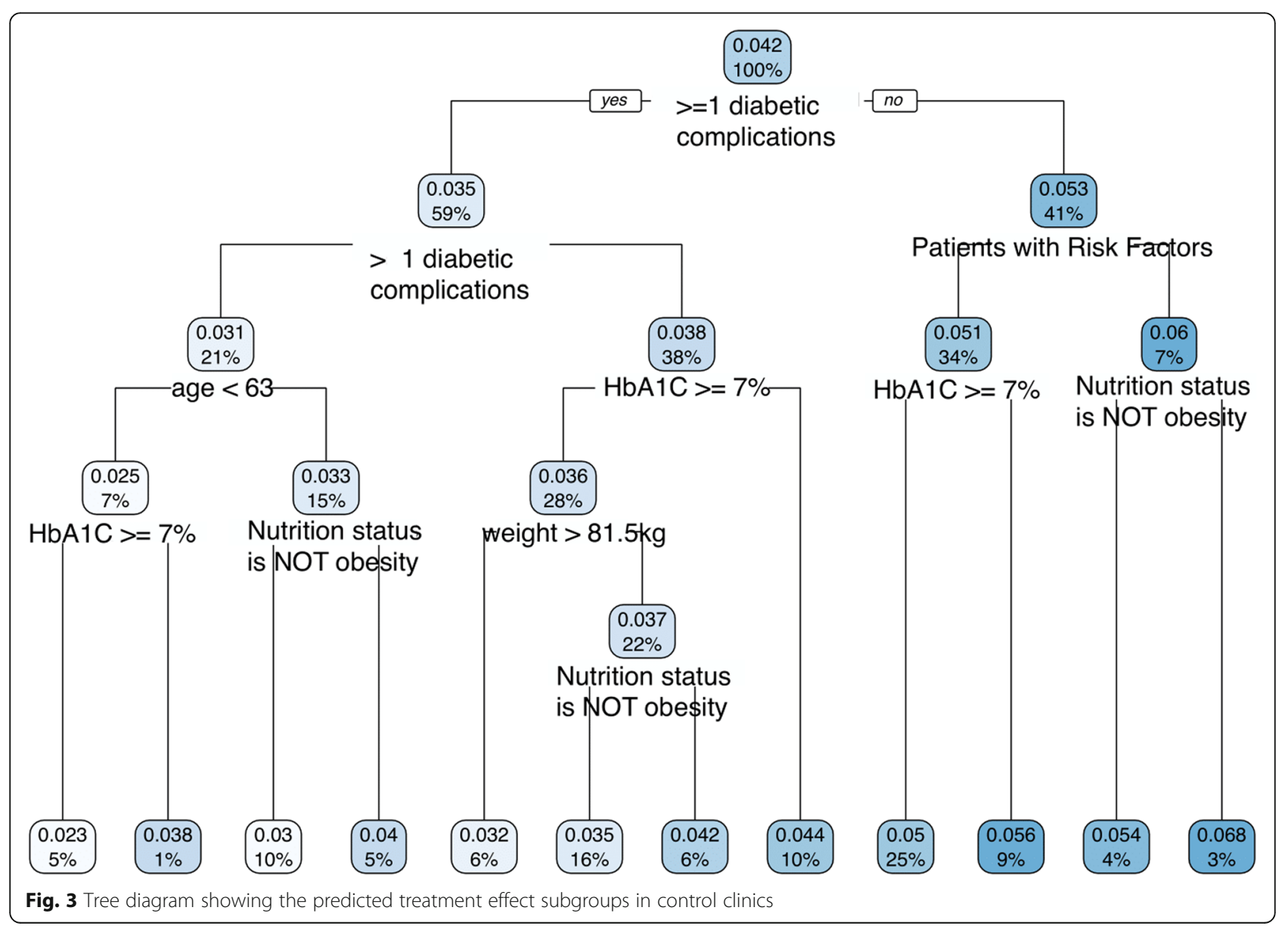


complications (Fig. 3). This result is not surprising as the magnitude of the reversal of the disease progression is more meaningful and harder to achieve among this subset. However, one sees no distinct sub-populations where either the program is universally effective or vice versa. Thus, for any group, using the average impact estimated (around 5\% improvement) is not an unrealistic estimate.

We also predicted the impact on a patient by patient basis for the conventional model clinics. We found that the predicted impact is quite like what was observed empirically in the DIABETIMSS clinics, that is, there is some variation, but one would expect about a 5\% improvement in glycemic control (on average) if the program were implemented in these clinics (Fig. 4).

The simulations revealed that the performance of the TMLE estimator is far superior to the simpler estimators (Figs. 5 and 6). Mainly, TMLE still works in cases when the parametric approaches fail to pick up the confounding and result in poor approximations for the true prediction model. More details can be found in the Supplemental Materials file.

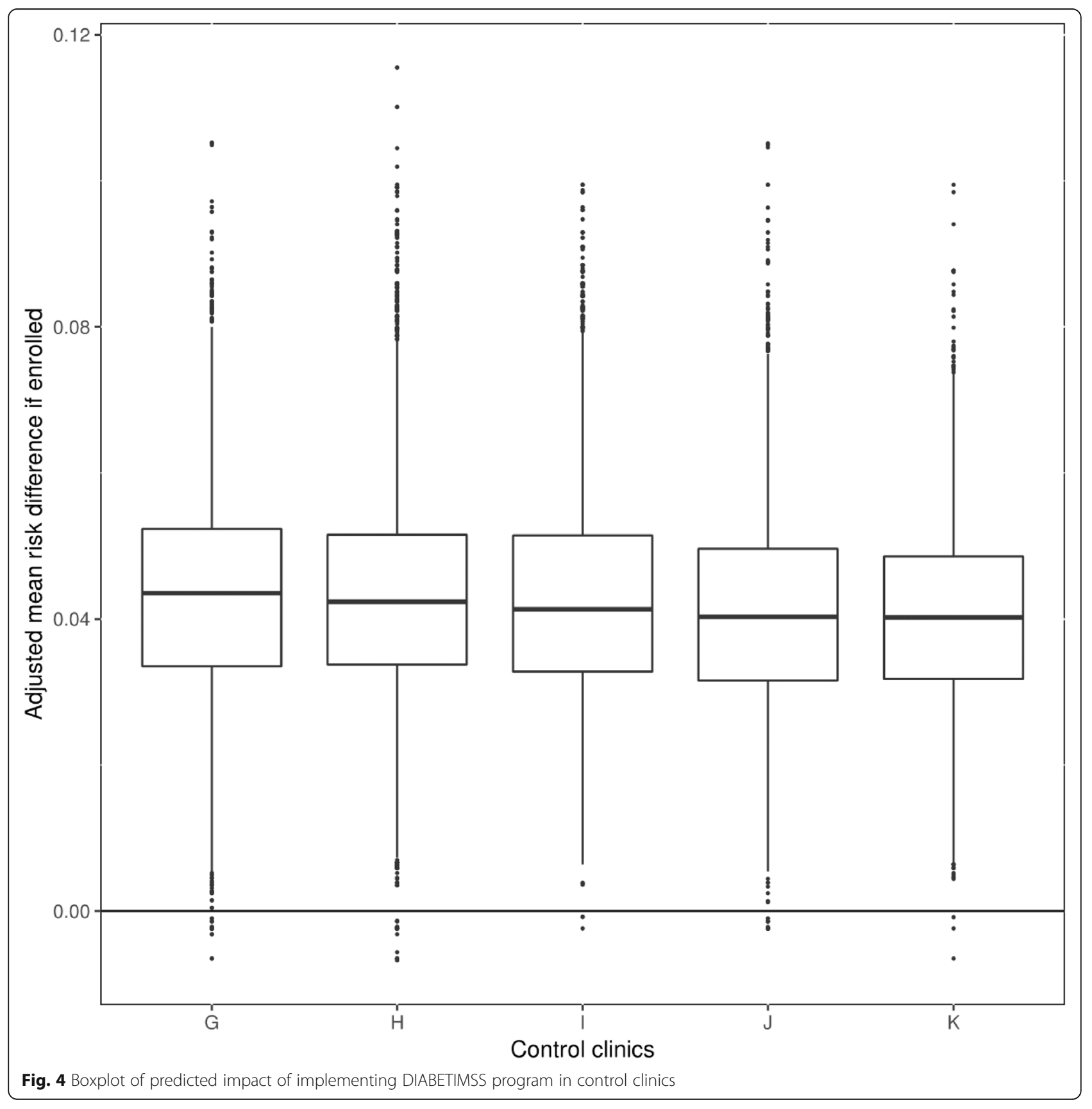




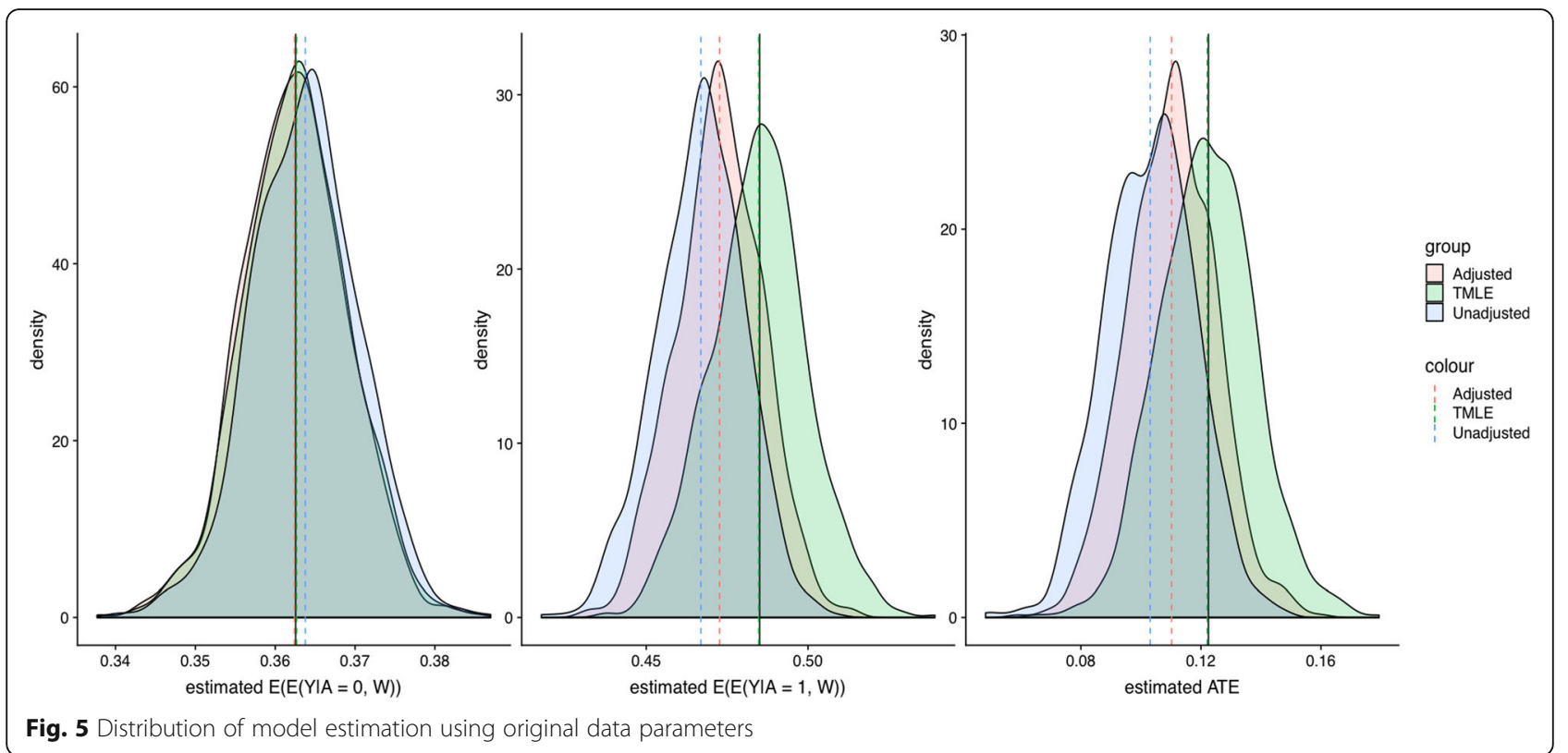

The sensitivity analysis that included process-of-care indicators as confounders showed more variable results, but the overall estimate averaged across all clinics did not change substantially (Additional file 1: Figure S1). Thus, adjustment by these indicators did not change the main conclusions of the analysis. One can see that the distribution of propensity scores (Fig. 7) has a larger proportion of the distribution at very low values (near 0 ) when the process-of-care indicators are included in the adjustment set. This result indicates other variable importance results (not included but available upon request) that suggests a weak association of these indicators with the outcome, but a strong correlation with the program, again suggesting they are problematic as confounders for our outcome (HbA1c indicator).

\section{Discussion}

The study provides evidence on the positive effect of DIABETIMSS program (pooled estimate of a $5 \%$ of improvement in glycemic control) and shows the potential and challenges in using routine observational patient data and machine learning methods to evaluate the performance of health interventions within complex healthcare institutions to inform decision-makers.

DIABETIMSS was implemented to improve diabetes care and health outcomes by addressing three critical

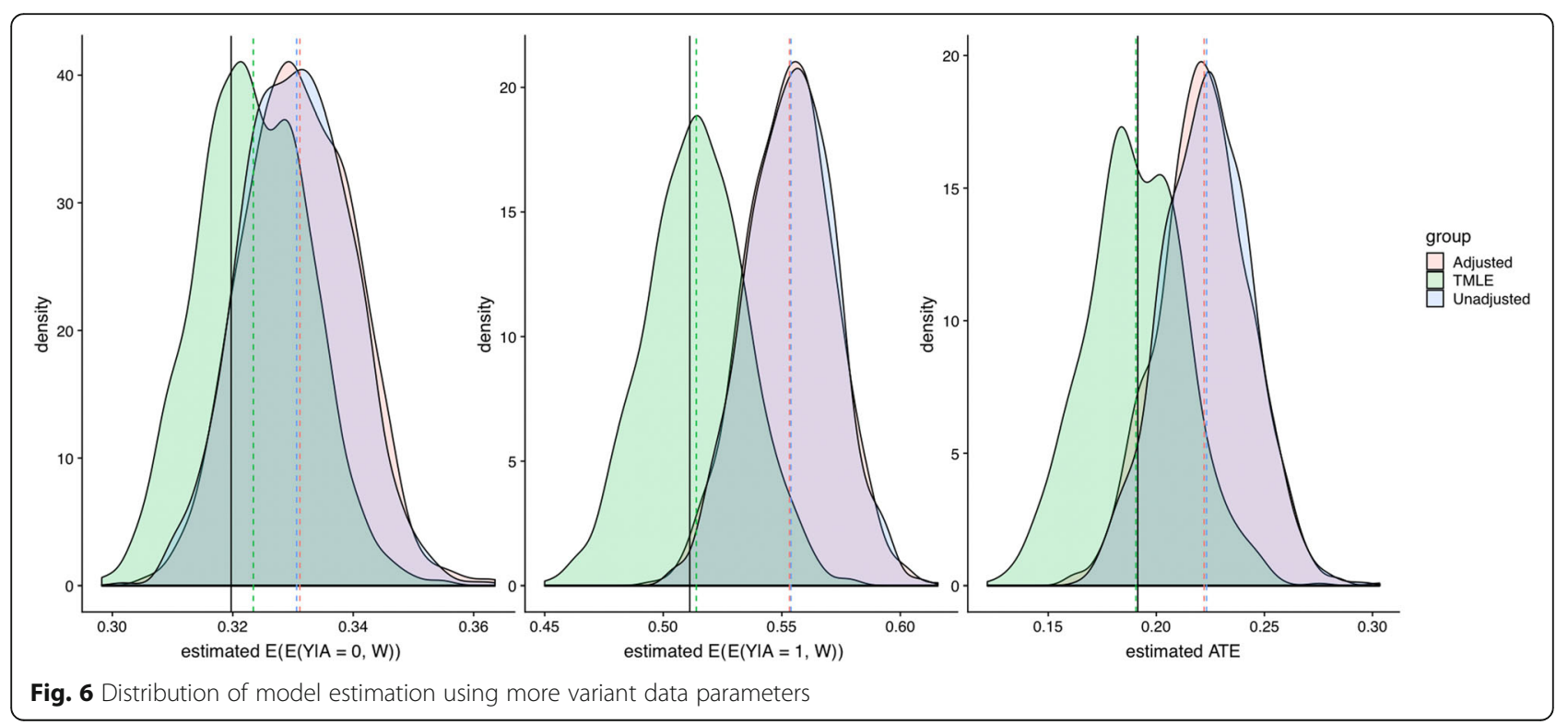




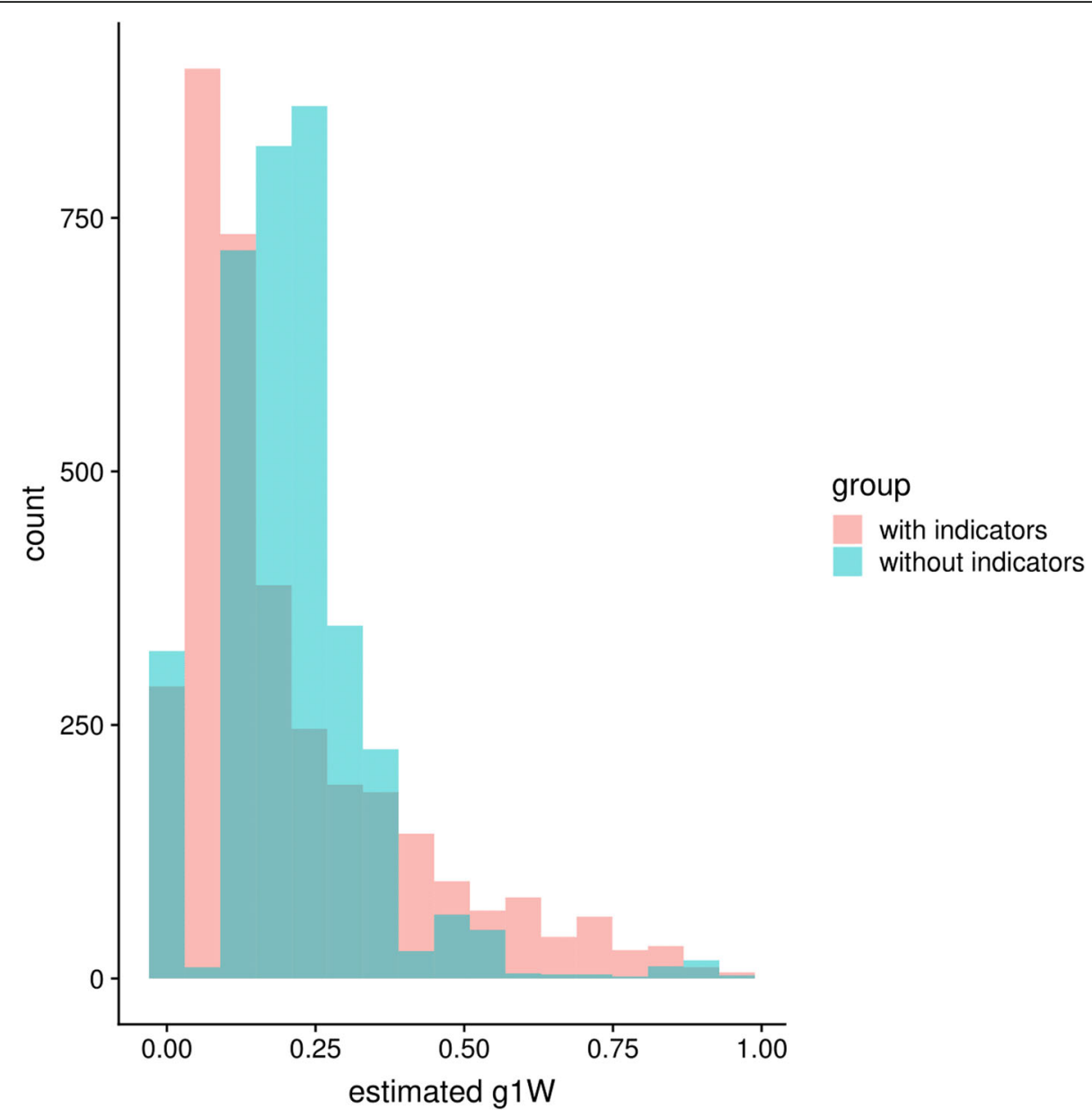

Fig. 7 Distribution of estimated propensity scores, $g(W)$ both including and excluding the process-of-care indicators

elements of the Chronic Care Model (CCM): 1) redesign of the delivery system through multidisciplinary teams, 2) decision support through evidence-based clinical guidelines, and 3) counseling and empowering of patients on self-management. Multiple clinical trials in different countries have tested these three elements, showing positive effects on the improvement of the processes of care and patients' outcomes [29, 30]. CCM has been increasingly advocated for effective management and control of NCDs within primary care [31]. Results from randomized controlled trials that have tested CCMs in primary care contexts in Europe show that compared to usual diabetes care, more patients reached treatment targets for blood pressure, and levels of blood sugar and cholesterol [32]. Experiences with CCMs in 8 Caribbean countries show improvements in baseline to follow up measures of blood glucose control and increases in the proportion of patients receiving a preventive practice or meeting quality-of-care indicators [33].

DIABETIMSS evaluation results are consistent with other CCMs interventions, revealing a small but essential impact of this program with an overall pooled estimate of 5\% improvement in glycemic control of T2D patients. Nonetheless, this slight increase in the percentage of T2D patients who achieved glycemic control call for further research, as IMSS' decision-makers require additional evidence to ascertain whether DIABETIMSS provide the interventions of the CCM optimally in compliance with evidencebased guidelines to assure high-quality care and better health outcomes [31, 34]. The evidence suggests that more significant benefits could be obtained through combining all six elements of the CCM that means incorporating the organizational changes that focus on creating a culture and mechanisms that promote safe, high-quality care, including the introduction of strategies to facilitate changes, and management of errors and quality control problems [30]. Another critical element of the CCM is the availability of timely and accurate health information systems to ensure program accountability and provide information for future improvement efforts [31]. 
The outcome variable of this study was $\mathrm{HbA} 1 \mathrm{C}<$ $7 \%$. Since 2000, this goal is recommended by the IMSS diabetes clinical guidelines, independently of patient age. However, since 2016, American Diabetes Association (ADA), highlighted that HbA1C measurement may have limitations primarily in older adults who have medical conditions that increase red blood cell turnover (e.g., hemodialysis, recent blood loss or transfusion, or erythropoietin therapy), which can falsely increase or decrease A1C. Therefore, for adults $\geq 65$ years of age ADA recommends specific glycemic control goals of $\mathrm{HbA} 1 \mathrm{C}<7.5 \%$ for healthy older adults with few coexisting chronic illnesses and $\mathrm{HbA} 1 \mathrm{C}<8.0 \%$ or $<8.5 \%$ for older adults with multiple coexisting chronic illnesses or instrumental impairments or cognitive impairment [35]. If we apply the ADA recommendation to our study, this could probably increase the effect of the DIABETIMSS on glycemic control of older patients; yet, further analysis is recommended to support this hypothesis.

To date, diabetes research that used machine learning methods, was focused primarily on biomarker identification, prediction of diagnosis and diabetes complications, with low emphasis on evaluation of healthcare programs [36]. Our study is one of the pioneers to evaluate the performance of an ongoing health program using machine learning methods and routine observational patient data to inform decision-makers. The study showed both the potential and challenges in using detailed observational patient data to evaluate the performance of a healthcare program. Though the estimates from standard regression were not radically different from those based upon less biased, machine learning methods, they do show enough difference to be important, mainly when the impacts apply to so many patients. The simulations show that the more complex targeted learning estimator does not harm performance when a more straightforward model provides an adequate approximation. However, usually, it is difficult to know at the beginning of the study whether standard methods will suffice, although, using such methods could increase the risk of misleading conclusions.

The present study shows the merits of using targeted learning approaches to evaluate the average performance of the intervention and explore its heterogeneity across different clinics. The analyses based on the distribution of patient characteristics also provide information regarding which clinics are most likely to benefit from future expansion of DIABETIMSS. The information provided could be the basis of informed cost-benefit analyses of DIABETIMSS or other programs.
Finally, the study allowed for creating the basis for an analytical framework that can be applied across complex health systems for evaluating programs/treatments using sophisticated machine learning technology but with simple interfaces for non-technical users.

The limitations of the analysis are related to the deficiencies of the available data. First, one of the limitations is related to the inclusion in the analysis of all patients with at least one visit to DIABETIMSS program during the calendar year. We based this decision on the fact that according to the DIABETIMSS internal handbook the first visit to DIABETIMSS should include individual patient consultation about self-care with the medical doctor and dietitian and group consultation with the nurse and social worker. It is expected that during this first visit, the patient will receive valuable information and motivation to his/her self-care and continue attending to the group education sessions on self-care. The average duration of the first patient consultation is $3 \mathrm{~h}$. Also, this decision can be explained by the fact that currently, IMSS lacks information on the number of visits and group educational sessions that each patient had in DIABETIMSS during one calendar year that is the usual time of DIABETIMSS exposure. The available information only includes the first consultation with the DIABETIMSS multidisciplinary team of health professionals. This situation impairs to identify the extent of exposure, particularly the optimal number of visits and group educational sessions to improve patient glycemic control. However, DIABETIMSS aim for a patient is to attend to 12 group educational sessions during one calendar year. IMSS could benefit from collecting routine information on the number of individual consultations and group sessions to evaluate the effect of the extent of exposure.

Second, the data had significant missing values, particularly for the outcome, making extrapolation of the results on those non-missing observations more problematic for the entire population. We assumed missing at random (MAR). This is the weakest identifiability assumption we could take and still estimate the impact of the program. MAR is also not identifiable empirically, so it is always non-testable. We found no observable difference in the principal component analysis of the covariates for patients with and without missing outcome (Additional file 1: Figure S2). In this case, we had a predictive set of covariates to predict the outcome (and are not missing) and using Super Learner insures that all information about the outcome contained in them is used. This is typically better than most handing of 
missing data (such as parametric imputation or inverse weighting).

\section{Conclusions}

Machine learning methods that use routine observational patient data is useful to evaluate the performance of an ongoing health program to inform decision-makers. Beyond the specific application to DIABETIMSS, the combination of methods and data suggest this type of study is valuable for evaluating programs and treatments within complex health care systems.

\section{Supplementary information}

Supplementary information accompanies this paper at https://doi.org/10. 1186/s12911-019-0950-5

\section{Additional file 1: Table S1. Description of covariates. Figure S1.}

Associations of DIABETIMSS and glucose control adjusting for process-ofcare variables (estimated difference in the percentage of those with $\mathrm{HbA1c}$ in two groups) Figure S2. Principal components analysis of covariates for patients with and without missing outcome. Figure S3. Comparison of associations of covariates and outcome by clinic. Figure S4. Distribution of DIABETIMSS treatment impacts among subjects in DIABETIMSS clinics.

\section{Abbreviations}

ATE: Average treatment effect; FMCs: Family medicine clinics; IMSS: Mexican Institute of Social Security; T2D: Type 2 diabetes.; TL: Targeted Learning

\section{Acknowledgements}

None.

\section{Authors' contributions}

YY - Conceptualized the statistical method, did the statistical analysis, contributed in drafting the manuscript. SVD - Conceptualized the study, performed the literature review, prepared and registered the study protocol, carried out the database extraction, participated in the discussion of study results, wrote the first draft of the manuscript and prepared it final version. DPM-Conceptualized the study, participated in the discussion of the study results and critically reviewed the manuscript for significant intellectual content. RPC -participated in the conceptualization of the study protocol, participated in preparing the manuscript, critically reviewed the manuscript for significant intellectual content. VBA - participated in the logistic of the fieldwork and critically reviewing the manuscript for significant intellectual content. $\mathrm{AH}$-Conceptualized the statistical method, did the statistical analysis and contributed in drafting and preparing the manuscript. All authors read and approved the final version of the manuscript, have participated sufficiently in the work to take public responsibility for appropriate portions of the content and agreed to be accountable for all aspects of the work in ensuring that questions related to the accuracy or integrity of any part of the work are appropriately investigated and resolved.

\section{Funding}

The study was supported by the Interamerican Development Bank. YY and $\mathrm{AH}$ received funds from IDB for working on this research project. DPM and RPC are employees of the IDB. DPM and RPC participated in the study design, discussion of the study results and critically reviewed the manuscript for significant intellectual content. As part of IDB staff they did not receive monetary compensations for their participation in this study.

\section{Availability of data and materials}

The datasets analysed during the current study are not publicly available due to the IMSS internal rules but are available from Alan Hubbard

(hubbard@berkeley.edu) on reasonable request.

\section{Ethics approval and consent to participate}

The Mexican Institute of Social Security (IMSS) Research and Ethics Committee approved the study (No. R 2017-785-036). This study did not require the patient consent to participate, as it performed a secondary data analysis of the 2012-2016 Electronic Health Record and laboratory databases of T2D patients. The Mexican Institute of Social Security (IMSS) Research and Ethics Committee approved access to the electronic health records and laboratory databases used in the research.This study did not require the patient consent for using the Electronic Health Record and laboratory information, as the data used in this study were de-identified; thus, it is not possible to trace any of the data to the individuals.

\section{Consent for publication}

Not applicable. The article does not include details, images, or videos relating to an individual person.

\section{Competing interests}

YY and $\mathrm{AH}$ received funds from Interamerican Development Bank (IDB) for working on this research project.

SVD and VBA are employees of the Mexican Institute of Social Security (IMSS). The opinions that SVD and VBA expressed in the article are the authors' own and do not necessarily reflect the views of the IMSS.DPM and RPC are employees of the IDB. The opinions that DPM and RPC expressed in the article are the authors' own and do not necessarily reflect the views of the IDB, its board of directors, or its technical advisers.

\section{Author details}

${ }^{1}$ Division of Epidemiology and Biostatistics, School of Public Health, University of California, Berkeley, USA. ${ }^{2}$ Epidemiology and Health Services Research Unit, CMN Siglo XXI, Mexican Institute of Social Security, Av. Cuauhtemoc 330, Col. Doctores, Mexico City, Mexico. Interamerican Development Bank, 1300 New York Ave NW, Washington DC 20577E, USA. ${ }^{4}$ Interamerican Development Bank, 6 Montrose Road, Kingston 6, Jamaica. ${ }^{5}$ Direccion de Prestaciones Medicas, Instituto Mexicano del Seguro Social, Mexico City, Mexico. ${ }^{6}$ Division of Epidemiology and Biostatistics, School of Public Health, University of California, Berkeley, USA.

Received: 1 July 2019 Accepted: 25 October 2019

Published online: 12 November 2019

\section{References}

1. Instituto Nacional de Salud Pública. Encuesta Nacional de Salud y Nutrición de Medio Camino 2016. (ENSANUT MC 2016). Informe final de resultados. INSP: Cuernavaca; 2016.

2. American Diabetes Association. Standards of medical Care in Diabetes -2019 abridged for primary care providers. Clin Diabetes. 2019; 37(1):11-34

3. Beckman JA, Creager MA. Vascular complications of diabetes. Circ Res. 2016; 118(11):1771-85.

4. Tseng $\mathrm{CH}$. Mortality and causes of death in a national sample of diabetic patients in Taiwan. Diabetes Care. 2004;27:1605-9.

5. Hemmingsen B, Lund SS, Gluud C, Vaag A, Almdal TP, Wetterslev J. Targeting intensive glycaemic control versus targeting conventional glycaemic control for type 2 diabetes mellitus. Cochrane Database Syst Rev. 2015;7:CD008143. https://doi.org/10.1002/14651858.CD008143.pub4 Cochrane Database Syst Rev. 2013.

6. Méndez-Durán A, Ignorosa-Luna MH, Pérez-Aguilar G, Rivera-Rodríguez FJ, González-Izquierdo JJ, Dávila-Torres J. Current status of alternative therapies renal function at the Instituto Mexicano del Seguro Social. Rev Med Inst Mex Seguro Soc. 2016;54(5):588-93.

7. Mexican Institute of Social Security. Report to the Federal Executive and Congress of the Union on the Financial Situation and Risks of the Mexican Institute of Social Security 2015-2016. México: IMSS; 2016. Informe al Ejecutivo Federal y al Congreso de la Unión Sobre la Situación Financiera y los Riesgos del Instituto Mexicano del Seguro Social 2016-2017

8. Pérez-Cuevas R, Doubova SV, Suarez-Ortega M, Law M, Pande A, RossDegnan D, Wagner A. Evaluating quality of care for patients with type 2 diabetes using electronic health record information in Mexico. BMC Med Inform Decis Mak. 2012;12:50 http://www.biomedcentral.com/1472-694 $7 / 12 / 5$ 
9. Doubova SV, Borja-Aburto VH, Guerra-y-Guerra G. Salgado de Snyder VN, Gonzalez-Block MA. Loss of job-related right to healthcare is associated with reduced quality and clinical outcomes of diabetic patients in Mexico. Int J Qual Health Care. 2018;30(4):283-90.

10. Bustos-Saldaña R, Bustos-Mora A, Bustos-Mora R. Control de Glucemia en Diabéticos Tipo 2. Rev Med Inst Mex Seguro Soc. 2005;43:393-9.

11. Salinas-Martínez A, Garza-Sebastegui M, Cobos-Cruz R. Diabetes y consulta médica grupal en atención primaria. Rev Méd Chile. 2009;137:1323-32.

12. Villarreal-Ríos E, Paredes-Chaparro A, Martínez-González L. Control de los pacientes con diabetes tratados sólo con esquema farmacológico. [probability of control of the patient with diabetes exclusively treated with pharmacological therapy]. Rev Med Inst Mex Seguro Soc. 2006;44:303-8.

13. Wagner $\mathrm{EH}$. Chronic disease management: what will it take to improve care for chronic illness? Effective Clinical Practice. 1998;1(1):2-4.

14. Wielawski IM. Improving chronic illness care. Birmingham: HSMC, University of Birmingham and NHS Institute for Innovation and Improvement; 2006.

15. León Mazón MA, Araujo Mendoza GJ, Linos Vázquez ZZ. DiabetIMSS. Eficacia del programa de educación en diabetes en los parámetros clínicos y bioquímicos. [Effectiveness of the diabetes education program (DiabetIMSS) on clinical and biochemical parameters]. Rev Med Inst Mex Seguro Soc. 2013;51(1):74-9.

16. Zuñiga-Ramirez MG, Villarreal Ríos E, Vargas Daza ER, et al. Perfil de uso de los servicios del módulo DiabetIMSS por pacientes con diabetes mellitus 2 Rev Enferm Inst Mex Seguro Soc. 2013;21(2):79-84.

17. Fiqueroa-Suárez ME, Cruz-Toledo JE, Ortiz-Aguirre AR, et al. Estilo de vida y control metabólico en diabéticos del programa DiabetIMSS. [Life style and metabolic control in DiabetIMSS program]. Gac Med Mex. 2014;150:29-34.

18. van der Laan MJ, Rose S. Targeted learning: causal inference for observational and experimental data. New York: Springer Science \& Business Media; 2011.

19. Schuler MS, Rose S. Targeted maximum likelihood estimation for causal inference in observational studies. Am J Epidemiol. 2017;185(1):65-73.

20. van der Laan MJ, Polley EC, Hubbard AE. Super learner. Stat Appl Genet Mol Biol. 2007;6(1):Article 25. https://doi.org/10.2202/1544-6115.1309.

21. Judea P, Glymour $M$, Jewell NP. Causal inference in statistics: A primer. West Sussex, United Kingdom: Wiley; 2016.

22. Gruber $\mathrm{S}$, van der Laan MJ. Tmle: an R package for targeted maxi- mum likelihood estimation. J Staf Softw. 2012;51(13):1-35.

23. Ihaka R, Gentleman R. R: a language for data analysis and graphics. J Comput Graph Stat. 1996;5(3):299-314.

24. Polley E, van der Laan M. SuperLearner: Super Learner Prediction. Technical report. R package version 2.0-6; 2012

25. Rubin D. Inference and missing data. Biometrika. 1976;63(3):581-90.

26. Therneau T, Atkinson B, Ripley B. rpart: Recursive Partitioning. R package version 4.1-0; 2012.

27. Lemon SC, Roy J, Clark MA, Friedmann PD, Rakowski W. Classification and regression tree analysis in public health: methodological review and comparison with logistic regression. Ann Behave Med. 2003;26(3):172-81.

28. Speybroeck N. Classification and regression trees. Int J Public Health. 2012; 57(1):243-6.

29. Lim LL, Lau ESH, Kong APS, Davies MJ, Levitt NS, Eliasson B, et al. Aspects of multicomponent integrated care promote sustained improvement in surrogate clinical outcomes: a systematic review and meta-analysis. Diabetes Care. 2018;41(6):1312-20.

30. Baptista DR, Wiens A, Pontarolo R, Regis L, Reis WC, Correr CJ. The chronic care model for type 2 diabetes: a systematic review. Diabetol Metab Syndr 2016;8:7. https://doi.org/10.1186/s13098-015-0119-z.

31. Wagner HE, Austin BT, Davis C, Hindmarsh M, Schaefer J, Bonomi A. Improving chronic illness care: translating evidence into action. Health Aff. 2001;20:64-78

32. Bongaerts BW, Müssig K, Wens J, Lang C, Schwarz P, Roden M, Rathmann W. Effectiveness of chronic care models for the management of type 2 diabetes mellitus in Europe: a systematic review and meta-analysis. BMJ Open. 2017;7(3):e013076. https://doi.org/10.1136/bmjopen-2016-013076.

33. Pan American Health Organization. Innovative Care for Chronic Conditions: organizing and delivering high quality Care for Chronic Noncommunicable Diseases in the Americas. Washington, DC: PAHO; 2013.

34. Worswick J, Wayne SC, Bennett R, Fiander M, Mayhew A, Weir MC, Sullivan KJ, Grimshaw JM. Improving quality of care for persons with diabetes: an overview of systematic reviews - what does the evidence tell us? Syst Rev. 2013;2:26.
35. American Diabetes Association. 12. Older Adults: Standards of Medical Care in Diabetes-2019. Diabetes Care. 2019:42(Suppl 1):S139-47.

36. Kavakiotis I, Tsave O, Salifoglou A, Maglaveras N, Vlahavas I, Chouvarda I. Machine Learning and Data Mining Methods in Diabetes Research. Comput Struct Biotechnol J. 2017;15:104-16.

\section{Publisher's Note}

Springer Nature remains neutral with regard to jurisdictional claims in published maps and institutional affiliations.

\section{Ready to submit your research? Choose BMC and benefit from:}

- fast, convenient online submission

- thorough peer review by experienced researchers in your field

- rapid publication on acceptance

- support for research data, including large and complex data types

- gold Open Access which fosters wider collaboration and increased citations

- maximum visibility for your research: over $100 \mathrm{M}$ website views per year

At $\mathrm{BMC}$, research is always in progress.

Learn more biomedcentral.com/submissions 